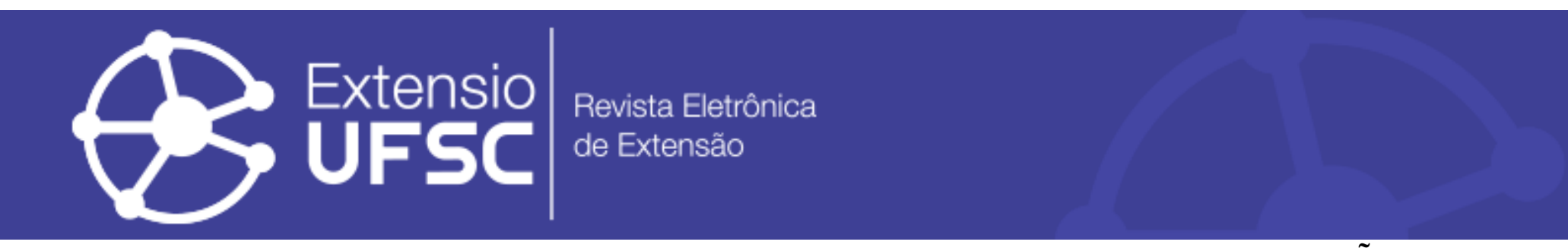

\title{
CURSO “COVID-19: CONHECENDO PARA SE PREVENIR" - EDUCAÇÃO EM SAÚDE E AÇÃO EXTENSIONISTA
}

\author{
Marcos Júnio Alves dos Santos \\ Universidade Federal dos Vales do Jequitinhonha e Mucurí \\ marcos.junio@ufvjm.edu.br \\ Roberto Allan Ribeiro Silva \\ Universidade Federal dos Vales do Jequitinhonha e Mucurí \\ roberto.allan@ufvjm.edu.br \\ Karla Taísa Pereira Colares \\ Universidade Federal dos Vales do Jequitinhonha e Mucurí \\ karla.colares@ufvjm.edu.br
}

\author{
Max Pereira Gonçalves \\ Universidade Federal dos Vales do Jequitinhonha e Mucurí \\ max.pereira@ufvjm.edu.br \\ Patrícia Nirlane da Costa Souza \\ Universidade Federal dos Vales do Jequitinhonha e Mucurí \\ patricia.souza@ufvjm.edu.br \\ Silas Silva Santana \\ Universidade Federal dos Vales do Jequitinhonha e Mucurí \\ santanasilvasilas87@gmail.com
}

\begin{abstract}
Resumo
Objetivo: Relatar a experiência vivenciada a partir do projeto "Covid-19: Conhecendo para se prevenir", desenvolvido por discentes, docentes e técnicos administrativos da UFVJM. Método: Foi ofertado à comunidade interna e externa à UFVJM um curso online, gratuito, sobre vários aspectos da Covid-19. Resultado: Obteve-se 404 inscrições de diferentes regiões do país, uma abrangência nacional. Essa adesão teve como consequência expressiva difusão de conhecimento com base científica sobre a pandemia para população de interesse, além de ajudar no combate às notícias falsas. Além disso, os membros executores apresentaram um aprimoramento da aprendizagem no uso das ferramentas de criação de conteúdo online e videoaulas. Conclusão: O compartilhamento de informações sobre a Covid-19 para a população mostrou-se positiva, contribuindo no combate à pandemia, e a experiência do projeto na percepção do extensionista foi excepcional a nível pessoal e acadêmico. Período: Desenvolvido entre 18/06/2020 e 13/08/2020.

Palavras-chave: Coronavírus; Pandemia; Projeto de Extensão; Prevenção; Covid-19.

\section{COURSE "COVID-19: KNOWING TO PREVENT YOURSELF" - HEALTH EDUCATION AND EXTENSION ACTION}

\section{Abstract}

Objective: Report the experience from the project "Covid-19: Knowing to be prevented" executed by graduates, professors and technicians at UFVJM. Method: Was offered to internal and external UFVJM community an online course free, on various aspects of Covid-19. Result: The course had 404 registrations obtained from different regions of the country, a national scope. This adhesion resulted in an expressive dissemination of scientifically based knowledge about the pandemic to the population of interest, in addition to helping to combat false news. In addition, the executors members showed an improvement of learning in the use of online content creation tools and video lessons. Conclusion: The sharing of information about Covid-19 for the population was positive, contributing to the fight against the pandemic, and the experience of the project in the perception of the extension worker was exceptional at a personal and academic level. Period: Developed between 06/18/2020 and 08/13/2020.

Keywords: Coronavirus; Pandemic; Extension Project; Prevention; Covid-19.

\section{CURSO "COVID-19: CONOCER PARA PREVENIR" - EDUCACIÓN EN SALUD Y ACCIÓN DE EXTENSIÓN}

Resumen

Objetivo: Relatar una experiencia de extensión del proyecto “Covid-19: Conocer para prevenir" ejecutado por estudiantes universitarios profesores y técnicos de la UFVJM. Método: Se prepararon lecciones en video sobre varios aspectos de Covid19 a la comunidad interna y externa de UFVJM. Resultado: El curso tuvo 404 inscripciones de diferentes regiones del país. Esta adhesión resultó en una amplia difusión del conocimiento con base científica sobre la pandemia a la población de interés, además de ayudar a combatir las noticias falsas. Además, los miembros ejecutores presentaron una mejora en el aprendizaje en el uso de herramientas de creación de contenido en línea y lecciones en video. Conclusión: El esclarecimiento de información sobre Covid-19 para la población resultó ser positivo, contribuyendo a la lucha contra la pandemia, y la experiencia del proyecto en la percepción del extensionista fue excepcional a nivel personal y académico. Periodo: Desarrollado entre el 18/06/2020 y el 13/08/2020.

Palavras clave: Coronavirus; Pandemia; Proyecto de Ampliación; Prevención; Covid-19. 
Curso "COVID-19: conhecendo para se prevenir - educação em saúde e ação extensionista

\section{INTRODUÇÃO}

A Covid-19 é uma infecção respiratória causada pelo novo Coronavírus, o SARS-CoV-2 (WHO, 2020). A doença foi identificada apenas em dezembro de 2019, na cidade de Wuhan, na China, e caracterizada, até então, como uma epidemia, apesar de indícios de que os primeiros casos surgiram em outubro do mesmo ano (SCHUCHMANN et al., 2020).

A pandemia decorrente da Covid-19 revelou ao mundo novas óticas sobre o modo de vida da população. O isolamento social, a mudança nos hábitos de higiene, uso constante de máscaras e o distanciamento social foram medidas recomendadas à sociedade com o intuito de combater a disseminação da doença.

O vírus SARS-CoV-2 possui uma transmissibilidade superior aos outros vírus do grupo SARS, contribuindo para o estabelecimento da pandemia. Sua transmissão ocorre de pessoa infectada para pessoa sadia através de gotículas de saliva, espirro, tosse com catarro, seguidos de contatos com a boca, nariz, olhos, ou também por contato com superfícies contaminadas (CDC, 2020). Tem um período de incubação entre 2 e 14 dias, e alguns indivíduos são assintomáticos (WHO, 2020). Entre os sintomas da Covid-19, os mais recorrentes são febre, tosse seca, dificuldade em respirar (dispneia), dor de cabeça e pneumonia. Além disso, a doença pode se agravar e evoluir para uma insuficiência respiratória progressiva, devido aos danos alveolares e à intensa resposta inflamatória resultante da infecção, podendo levar o paciente à morte (ZHOU et al., 2020). Desta forma, as principais formas de prevenção são: o uso de máscara, cobrir tosse e espirro, higienização das mãos, manter distância das pessoas e não tocar as mucosas (CDC, 2020).

Um estudo feito com outros coronavírus mostrou que o tempo que o vírus consegue permanecer sobre superfícies e manter seu poder infectivo dependerá do tipo de material, podendo variar de 2 horas, como ocorre com o alumínio, a 9 dias, como ocorre em plásticos, mas, a higienização das superfícies reduz significativamente as chances de se contrair a infecção por estes meios (KAMPF, 2020). Além disso, as mãos representam uma importante fonte de infecção pelo SARS-CoV-2, sendo a higienização das mãos uma das medidas preventivas mais relevantes, contribuindo significativamente para redução das infecções (MARRA et al., 2016; KINGSTON et al., 2016; GOLDMANN, 2006).

Analisando essas questões supracitadas, observou-se a necessidade de divulgação das normas técnicas e do conhecimento científico com o intuito de auxiliar as pessoas a se protegerem desta doença no seu cotidiano, de conhecer e lidar com a saúde mental do indivíduo durante a pandemia. Nesse sentido foi idealizado o projeto, objeto deste relato de atividade extensionista, 
Curso "COVID-19: conhecendo para se prevenir - educação em saúde e ação extensionista

intitulada "Covid-19: Conhecendo para se prevenir", e executada por discentes, docentes e servidores técnicos administrativos da Universidade Federal dos Vales do Jequitinhonha e Mucuri (UFVJM) do campus Janaúba - MG. Esta iniciativa foi oferecida tanto à comunidade interna quanto à externa da UFVJM, um curso gratuito em modalidade online, com o objetivo de esclarecer temas como o uso correto de máscaras, a forma correta de higienizar as mãos e o ambiente, além de explicar a doença e oferecer dicas de como lidar com as emoções em tempos de pandemia. O projeto Covid-19: Conhecendo para se prevenir, foi iniciado após a aprovação no edital PROEXC 03/2020, da Pró-Reitoria de Extensão e Cultura (PROEXC) da UFVJM. Este projeto apresentou grande importância, visto que, desde o seu lançamento até o presente momento, a pandemia continua estável, exigindo que a população adote o isolamento social e práticas corretas de combate ao vírus. Desta forma, o presente artigo tem como objetivo relatar a experiência do discente extensionista bolsista sobre a execução do projeto e a percepção dos impactos no público-alvo e na equipe executora do projeto.

\section{MATERIAIS E MÉTODOS}

Trata-se de relato de um curso de extensão universitária, denominado "Covid-19: Conhecendo Para Se Prevenir", desenvolvido por acadêmicos, técnicos administrativos e docentes da UFVJM do curso de Bacharelado Interdisciplinar em Ciência e Tecnologia.

Estrutura do curso e equipe executora: A atividade extensionista foi realizada por um grupo de cinco discentes de graduação, três docentes doutores nas áreas de biologia celular, imunologia e microbiologia, e três técnicos administrativos, sendo um enfermeiro pós-graduando, uma bióloga mestre em ensino em saúde, e uma psicóloga pós-graduada em psicanálise. O público-alvo foi toda comunidade interna e externa interessada em informações sobre a Covid-19. Com o intuito de apresentar o conteúdo de forma didática, o curso foi dividido em seis módulos com temas importantes na prevenção e combate à pandemia, de forma que estes seguiram uma ordem a fim de se completarem, como exemplificado na Figura 1. Cada módulo foi liderado por um docente ou técnico administrativo da UFVJM, de forma que os discentes se dividiram dentro destes módulos para auxiliar na produção dos conteúdos. 
Curso "COVID-19: conhecendo para se prevenir - educação em saúde e ação extensionista

Figura 1- Conteúdos do curso "Covid-19: Conhecendo para se prevenir", organizados pelos títulos de cada módulo oferecido.

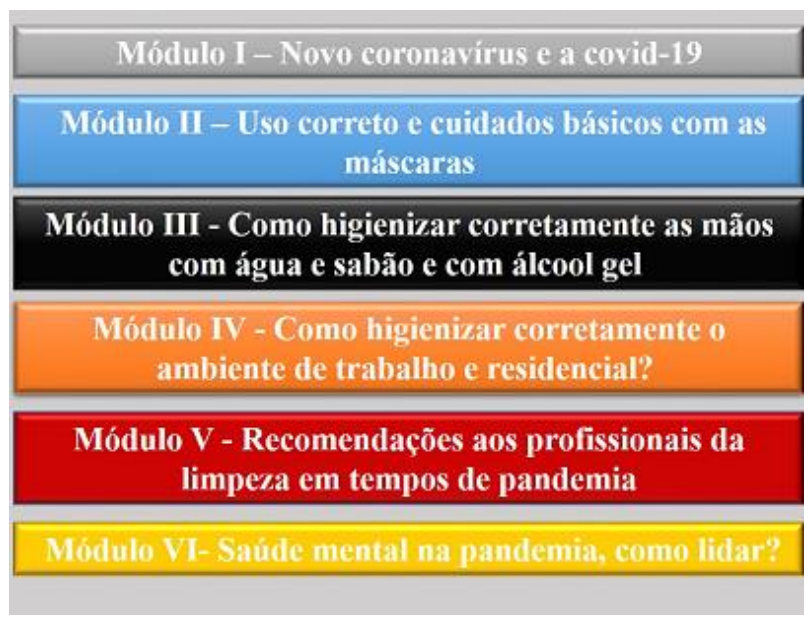

Fonte: elaborado pelos autores.

Todo o trabalho seguiu-se de datas e prazos para atendimento hábil à comunidade. $\mathrm{Na}$ Tabela 1 estão as informações de datas seguidas pelo projeto.

Tabela 1. Atividades e datas executadas pelo projeto.

\begin{tabular}{c|c}
\hline ATIVIDADES & DATAS \\
\hline Criação do edital PROEXC & $18 / 06 / 2020$ \\
Estudos bibliográficos e início das gravações & $27 / 06 / 2020$ \\
Início das inscrições & $06 / 07 / 2020$ \\
Disponibilidade do primeiro módulo do curso & $03 / 08 / 2020$ \\
Encerramento dos módulos & $13 / 08 / 2020$ \\
\hline
\end{tabular}

Plataforma de divulgação do curso: A plataforma utilizada para disponibilizar os vídeos para acesso dos inscritos foi o Google Classroom, como demonstrado na Figura 2, que mostra um print da página inicial personalizada do curso no ambiente virtual. Cada módulo ficou disponível para acesso dos alunos em datas pré-determinadas no cronograma de execução do curso, de forma que além dos vídeos, avaliações em cada módulo também eram postadas, para fins de emissão dos certificados dos inscritos.

Assim, o primeiro trabalho da equipe foi estudar as técnicas para gravação, edição e disposição dos vídeos para visualização dos alunos, bem como estudar tutoriais para aprender a trabalhar na sala do Google Classroom. Alguns dos programas utilizados para criação dos vídeos foram o Programa oCam para gravações de tela, programa Filmora para edição dos vídeos e plataforma Powtoon para criação de animações. 
Curso "COVID-19: conhecendo para se prevenir - educação em saúde e ação extensionista

Figura 2- Página inicial da plataforma online utilizada (Google Classroom), no curso "Covid-19: Conhecendo para se prevenir".

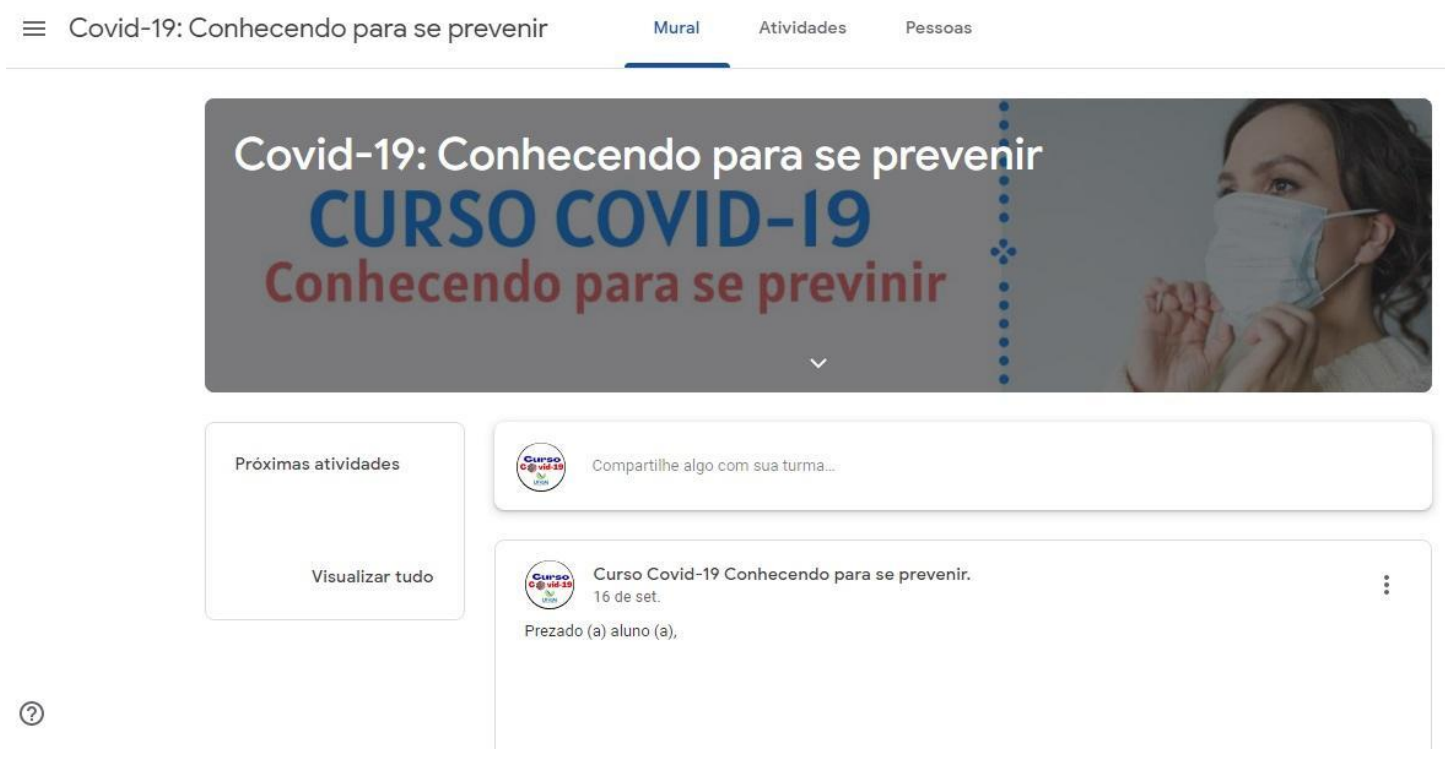

Fonte: elaborado pelos autores

Fundamentação teórica para elaboração do curso: Com o intuito de fundamentar cientificamente as videoaulas, a primeira etapa foi categorizar os temas que seriam abordados e realizar extensiva revisão da literatura com base em artigos, recomendações e/ou nota técnicas de órgãos como Organização Mundial da Saúde (WHO, 2020) e Agência nacional de vigilância sanitária (ANVISA, 2020).

Divulgação do curso e inscrições dos participantes: Concomitantemente, enquanto ocorriam estudos para elaboração dos vídeos, houve também a divulgação e levantamento das inscrições no mesmo. A divulgação foi dirigida para todo público, seja dentro ou fora da unidade universitária, com intuito de atingir pessoas que estivessem em qualquer grau de escolaridade ou profissão com um único interesse de aprender sobre a pandemia da Covid-19. Redes sociais e material de divulgação foram estruturados, e as inscrições realizadas por formulário online. A Figura 3A é ilustrativa do logo que foi criado para o curso, sendo exibida tanto nas peças de divulgação quanto nas vinhetas de abertura de cada vídeo dos módulos. Além disso, como observado na Figura 3B, foram criados folders divulgados tanto no Instagram oficial do curso quanto através dos e-mails que foram disparados para diversas universidades em todo o país. Ao final, o trabalho de divulgação do curso rendeu 404 inscritos. 
Curso "COVID-19: conhecendo para se prevenir - educação em saúde e ação extensionista

Figura 3- Imagens utilizadas no processo divulgação do curso "Covid-19: Conhecendo para se prevenir" para o público. O logo do curso (A) e o folder de divulgação do curso (B).

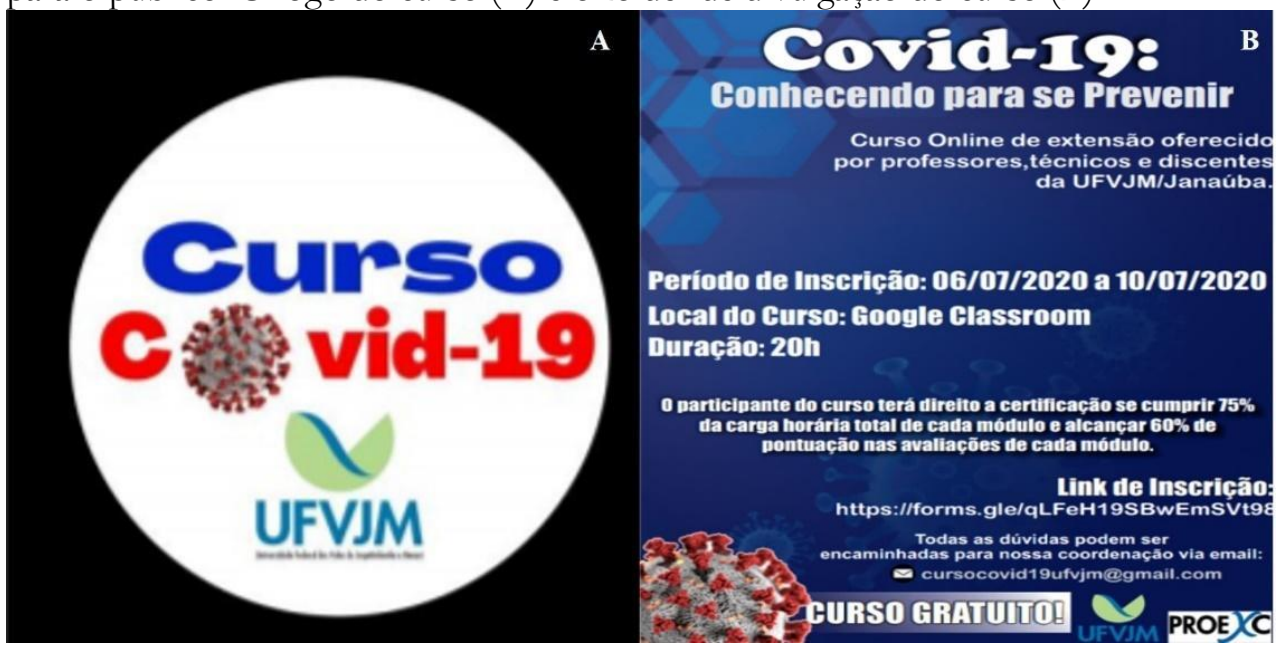

Fonte: elaborado pelos autores

\section{RESULTADOS E ANÁLISES}

O trabalho de divulgação, aliando a potência das redes sociais e o contato direto por e-mail com diversas instituições de ensino superior de todo o Brasil, resultou em 404 inscrições. Salientase que no curso existiram variados perfis de inscritos: com relação ao sexo, maioria dos inscritos se caracterizam como mulheres, com as mais variadas faixas escolares, desde profissionais já formados, aqueles que possuem apenas o ensino médio ou que estão em formação superior.

Um dos pontos que podem ter contribuído para o curso ter atingido diversos níveis de escolaridade foi o fato de os vídeos serem editados em uma linguagem popular e de fácil compreensão, democratizando o acesso às informações e sendo acessível a toda população interessada, não necessitando nenhum conhecimento prévio específico sobre o tema em questão. Além disso, pelo isolamento social vigente, o uso de recursos virtuais para a orientação da comunidade acerca da prevenção contra Covid-19 se mostrou eficiente ao permitir que 404 pessoas fizessem sua inscrição no projeto, independente da localidade onde estavam situados ou da escolaridade.

A educação a distância é um desafio, mas não deve ser entendida como uma barreira. Fernandes (2020) cita sobre o erro ao se relacionar a categoria Educação a Distância (EAD) com a separação física entre docentes, tutores e discentes, não fazendo com que a distância seja responsável pela desconexão entre os envolvidos. A apresentação de um curso em vídeo pode ser 
Curso "COVID-19: conhecendo para se prevenir - educação em saúde e ação extensionista

tomada como muito positiva, pois pode transmitir verossimilhança, usando elementos da imagética das pessoas para esse efeito (XAVIER 2017 apud FERNANDES, 2020). Contudo, o trabalho com vídeo exige técnica e conhecimento sobre áudiovisual, além do já necessário sobre o tema discutido.

Após o fim das gravações das videoaulas, o curso foi disponibilizado na plataforma Google Classroom para apreciação dos inscritos, totalizando 20 horas de videoaulas, entrevistas, mesas redondas, dentre outros formatos com informações técnicas-científicas sobre a Covid-19. O Google Classroom se mostrou uma ferramenta bastante prática e didática, uma vez que foi possível postar todas as videoaulas, interagir com os participantes via chat, bem como acompanhar o andamento dos participantes, à medida que entregavam as atividades ao final de cada módulo. Como evidenciado no trabalho de Harayama e colaboradores (2020), uma plataforma como Google Classroom permite a inserção de vídeo, questionários, contribuindo bastante para interatividade dos alunos e tutores simulando uma sala de aula. Essa interatividade também foi observada no presente curso, com interação praticamente diária dos inscritos e da equipe executora. Assim, como relatado por Franco e colaboradores (2003), as aulas em ambiente virtual podem permitir uma maior inclusão de diferentes alunos, bem como sua forma organizada e segura facilita a entrega de atividades, beneficiando tanto os alunos como aos tutores.

Ainda em relação à plataforma online utilizada, é importante ressaltar a interação de alunos e tutores. Cada postagem feita deixava espaço para que os alunos fizessem seus feedbacks e suas dúvidas para serem respondidas posteriormente. Isso se mostra bastante interessante porque, em alguns casos, ocorre em modo de tempo real, mantendo o tempo interativo da plataforma. É interessante notar que em relação aos comentários, muitos deles foram construtivos e elogiosos, fazendo com que a equipe tenha tido sentimento de busca de melhorias.

No curso foram discutidos vários temas importantes e que necessitavam de esclarecimentos para a população. Dentre os temas abordados, segue uma breve descrição dos módulos apresentados:

Módulo I - Novo coronavírus e a Covid-19. Carga horária 3 horas. O primeiro módulo introduziu informações sobre questionamentos, origens, hipóteses, dispersão e a globalização do vírus (VARGAS, 2020), trazendo conhecimentos gerais sobre o que é um vírus e como eles se multiplicam. Com as informações iniciais sobre o vírus, seguiu-se uma descrição biológica do vírus SARS-CoV-2, desenvolvendo em seguida discussões sobre a Covid-19, seu período de incubação e transmissão. Nesse módulo também foi desenvolvido o subtema "Mitos e verdades sobre a Covid-19", no intuito de sanar dúvidas sobre informações distorcidas sobre a doença e sua origem. 
Curso "COVID-19: conhecendo para se prevenir - educação em saúde e ação extensionista

Módulo II - Uso correto e cuidados básicos com as máscaras. Carga horária 2 horas. Este módulo teve a proposta de apresentar de forma didática o tema utilização de máscaras no contexto da pandemia da Covid-19, de forma que a principal disciplina envolvida neste módulo é a biossegurança, com ênfase no que é recomendado para o novo Coronavírus. Foram abordados conceitos de extrema importância para a comunidade, de forma a fomentar o conhecimento sobre a utilização deste Equipamento de Proteção Individual (EPI) tão importante no enfrentamento da pandemia. Desta forma, a divisão dos temas abordados neste módulo foi sobre a importância das máscaras durante a pandemia e quais tipos são recomendados em cada situação (N95, cirúrgica, caseira de tecido e caseira com filtro, máscaras de acrílico), o uso correto de máscaras caseiras e cirúrgicas (como colocar e retirar as máscaras, o que não fazer ao se utilizar máscaras, descarte adequado), e o manual para higienização de máscaras caseiras e para sua confecção.

\section{Módulo III - Como higienizar corretamente as mãos com água e sabão ou com álcool em} gel. Carga horária 2 horas. O módulo em questão cuidou de trazer uma introdução sobre o contexto histórico sobre a higienização das mãos e sua importância (SANTOS, 2002). Sendo subdividido em como higienizar as mãos de maneira correta, os riscos da não higienização das mãos, mostrar aos participantes como as mãos continuam infectadas se não forem higienizadas corretamente, a higienização das mãos utilizando sabão, detergente, álcool 70\% ou álcool em gel $70 \%$. Ao final, foi encorajado aos inscritos que produzissem um vídeo higienizando as mãos para serem avaliados quanto à maneira correta desta importante medida de prevenção.

Em relação à higienização das mãos, esta é considerada como a medida mais importante e eficaz na prevenção e controle de infecções, sendo uma prática rotineira, de baixo custo e com indicações sustentadas por fundamentação científica sólida. Entretanto, a adesão ao procedimento ainda é descrita como insuficiente em todo o mundo (MARRA et al., 2014; KINGSTON et al., 2016).

\section{Módulo IV - Como higienizar corretamente o ambiente de trabalho e residencial? Carga} horária 2 horas. Este módulo elaborou discussões sobre os ambientes de convívio das pessoas e os cuidados com a higiene nestes. Sendo subdividido em temas como o ambiente e a transmissão de infecções, a estabilidade do SARS-CoV-2 em aerossol e nas diferentes superfícies, os conceitos de limpeza, tipos e métodos de limpeza, sobre como realizar a higienização do ambiente de trabalho e residencial e a entender um pouco sobre os principais produtos utilizados na limpeza de superfícies como sabões e detergentes, álcool e compostos liberadores de cloro ativo. 
Curso "COVID-19: conhecendo para se prevenir - educação em saúde e ação extensionista

Módulo V - Recomendações aos profissionais da limpeza em tempos de pandemia. Carga horária 3 horas. Para promover a segurança de todos em um ambiente de trabalho, este módulo foi destinado aos profissionais da limpeza objetivando orientá-los quanto à correta higienização dos espaços físicos, visando evitar a disseminação da doença, orientando-os quanto à forma correta do uso de EPIs e do uso de desinfetantes, além de oferecer recomendações básicas para evitar a autocontaminação desses profissionais, enquanto realizam os procedimentos de higienização. Este módulo foi subdivido com os riscos a que estão expostos os profissionais de limpeza, os conceitos sobre limpeza, os princípios básicos para a limpeza e desinfecção de superfícies, o uso de EPIs, e os cuidados durante a paramentação e desparamentação.

Vale ressaltar que este módulo não consistiu em uma capacitação completa destes profissionais. O módulo apenas objetivou oferecer algumas recomendações a estes funcionários de forma simples e dinâmica, ajudando nas orientações deles dentro deste contexto de pandemia.

Módulo VI- Saúde mental na pandemia, como lidar? Carga horária 3 horas. O último módulo discutiu temas envolvendo o conceito de saúde e saúde mental e os determinantes da saúde mental, os impactos da pandemia na saúde mental de indivíduos inseridos em diferentes contextos, as reações mais frequentes dos indivíduos durante uma pandemia, os impactos específicos da Covid19, as estratégias de cuidado psíquico em situações de pandemia, e quando uma reação psicossocial considerada esperada se torna sintomática e precisa ser encaminhada para atendimento qualificado, e seus efeitos tardios mais recorrentes. Os tópicos foram baseados principalmente em trabalhos como o de Schmidt et al. (2020), Maia et al. (2020), em recomendações em saúde mental da Fiocruz (NOAL et al., 2020) e Organização Mundial de Saúde (WHO, 2020).

$\mathrm{Na}$ visão do extensionista, a avaliação do curso com os temas tratados nos seis módulos, importantes para a pandemia da Covid-19, conseguiu abordar com sucesso tópicos desde as características do vírus até a saúde mental, contribuindo para a divulgação de informações científicas e para um melhor entendimento por parte da população de assuntos tão importantes em um momento tão delicado como este da pandemia.

Outro aspecto interessante de se notar é que vários termos importantes foram popularizados após o início da pandemia. A partir da análise crítica do curso, a equipe executora selecionou algumas palavras-chave que foram muito citadas nos módulos apresentados, e dispensou-as em forma de nuvem de palavras para exemplificar este novo vocabulário do nosso dia a dia (Figura 4). Na percepção do discente extensionista, é extremamente importante entender 
Curso "COVID-19: conhecendo para se prevenir - educação em saúde e ação extensionista

o significado dessas palavras e evitar qualquer tipo de informação falsa que possa ser vinculada em cada uma dessas palavras e temas.

Figura 4- Principais palavras encontradas no curso dispostas em nuvem de palavras.

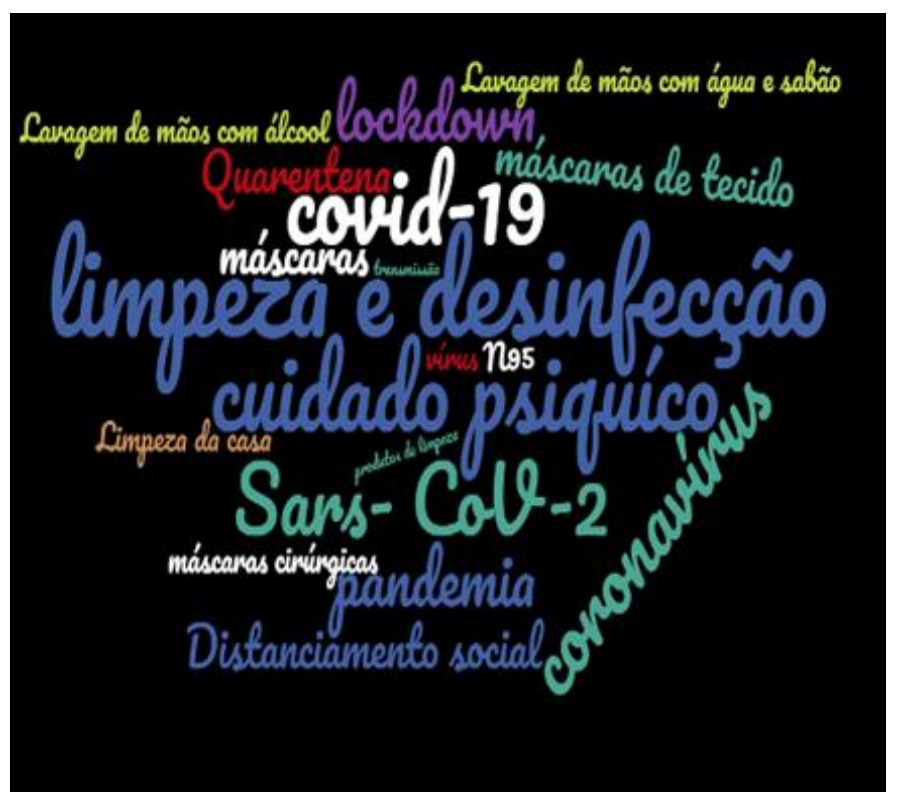

Fonte: elaborado pelos autores

A participação dos alunos de graduação nesse projeto se mostrou de grande importância, dando a eles a oportunidade de aprender diferentes ferramentas tecnológicas para criação das videoaulas, além, é claro, de aprofundar os conhecimentos sobre o novo coronavírus. O fomento da importância do conhecimento acerca das temáticas, orientada por docentes, e feita por artigos e estudos com base científica também é relevante, uma vez que denota a importância quando falamos de divulgação de conhecimento à comunidade, como também na construção de metodologia científica dos alunos no meio acadêmico.

O projeto também se mostrou importante para a comunidade, de modo que pessoas das mais diversas idades, formações e/ou conhecimento específico na área pudessem receber em suas casas, sem precisar violar o isolamento social, conteúdo de qualidade, rico em informações para prevenção da doença e combate às fake news.

As ações extensionistas têm valor na aproximação da comunidade acadêmica e a população, permitindo a participação da comunidade ao conhecimento de produção científica (PASSAMAI et al., 2020), como evidenciado em diversos trabalhos (MELO et al., 2020; POST et al., 2021; COELHO et al., 2020), que relatam a importância da extensão por vias remotas, como forma de não interromper seus trabalhos pela impossibilidade de encontro presencial devido à pandemia. 
Curso "COVID-19: conhecendo para se prevenir - educação em saúde e ação extensionista

Além disso, as ações extensionistas que têm como foco a promoção da saúde são importantes ferramentas na transformação de indivíduos promotores de saúde e multiplicadores de conhecimentos adquiridos dentro do espaço em que estão inseridos (FONSECA et al., 2020).

Com base nas respostas dos alunos manifestadas em comentários na plataforma, e no desempenho dos tutores (discentes, docentes e técnicos administrativos da UFVJM), infere-se que o projeto foi bem-sucedido, alcançando seus objetivos em orientar a comunidade dentro e fora do meio acadêmico sobre cuidados e prevenção para com a Covid-19, promovendo a educação em saúde. Evidencia-se a necessidade de preparo prévio dos profissionais acerca das ferramentas utilizadas, para se atingir melhor aproveitamento e aprendizado dos alunos.

\section{CONSIDERAÇÕES FINAIS}

A pandemia da Covid-19 tem apresentado desafios nas mais diversas áreas, em especial à educação. O número alarmante de notícias falsas e sem base científica corroboram o impacto deste projeto, ao levar informações científicas seguras para as comunidades externa e acadêmica, sem necessitar violar o isolamento social presente.

Entre os desafios enfrentados pela equipe, destaca-se o desenvolvimento de toda atividade por encontros virtuais, o estudo de novos conhecimentos práticos na elaboração de material virtual que vão além dos enfrentados em uma atividade presencial. Porém, o curso se encerra como proveitoso, visto que sua meta de levar informações básicas sobre os cuidados com a pandemia de SARS-CoV-2 foi levada aos inscritos.

Esse projeto encerrou-se como uma ação que atendeu às demandas acadêmicas e da comunidade externa, colaborando para maior conhecimento dos discentes tutores na disseminação e busca de informação científica confiável, e na produção de ensino remoto, além de aproximar os discentes, técnicos e docentes da população.

Conclui-se que os objetivos propostos neste curso foram alcançados e evidencia-se o potencial das ferramentas virtuais em propiciar ambientes de aprendizagem pouco explorados antes da pandemia, apontando para a necessidade de aprimoramento e domínio do uso de tecnologias para o ensino.

\section{REFERÊNCIAS}

AGÊNCIA NACIONAL DE VIGILÂNCIA SANITÁRIA (Brasil). Segurança do Paciente:

Higienização das mãos. Brasilia, DF: Ministério da saúde, 2020. Disponível em: 
Curso "COVID-19: conhecendo para se prevenir - educação em saúde e ação extensionista

https://www.anvisa.gov.br/servicosaude/manuais/paciente_hig_maos.pdf. Acesso em: 15 jan. 2021.

ARAÚJO, R.; PANERAI, T. Relato de Experiência de Blended Learning: O Moodle e o Facebook como Ambientes de Extensão da Sala de Aula Presencial. In: Workshop de Informática na Escola. [Anais]. Vol. 1. No. 1. 2012. Disponível em: https://brie.org/pub/index.php/wie/article/view/2121. Acesso em: 10 fev. 2021.

CDC - CENTERS FOR DISEASE CONTROL AND PREVENTION. How Coronavirus Spreads. 2020. Disponível em: https://www.cdc.gov/coronavirus/2019-ncov/prevent-gettingsick/how-covid-spreads.html. Acesso em: 29 mar. 2021

COELHO, A. L. C.; BATISTA, C.; MATTOS, D.; FANTUZZI, L.; DEGANI, M. Projeto de extensão "Ciência Política nas Escolas": adaptação e oportunidades de crescimento em tempos de pandemia. Raízes e Rumos, Rio de Janeiro, v.8 n.1, p. 48-68, 2020. Disponível em: http://seer.unirio.br/index.php/raizeserumos/article/view/10277. Acesso em: 20 jan. 2021.

FERNANDES, F. B. M. As videoaulas como tecnologias acessórias à leitura de textos acadêmicos: estudo de caso a partir do curso de extensão a distância pensamento lésbico contemporâneo. Revista Docência e Cibercultura, v. 4, n. 1, p. 298-321, 2020. Disponível em: https://www.e-publicacoes.uerj.br/index.php/re-doc/article/view/47451. Acesso em: 20 mar. 2021.

FRANCO, M. A.; CORDEIRO, L. M.; CASTILLO, R. A. F. del. O ambiente virtual de aprendizagem e sua incorporação na Unicamp. Educação e Pesquisa, São Paulo, v. 29, n. 2, pág. 341-353, 2003. Disponível em: https://www.scielo.br/scielo.php?pid=S151797022003000200011\&script=sci_arttext\&tlng=pt. Acesso em: 04 dez. 2020.

FONSECA, Y. S.; MANGANELLI, L. A. G.; BORGES, G. F.; ALVES, C. O.; BARBOSA, G. A.; CORREIA, A. P.; MASCARENHAS, A. G. Ação extensionista de promoção da saúde para estudantes universitários. Extensio: Revista Eletrônica de Extensão, Florianópolis, v. 17, n. 35, p. 81-95, 2020. Disponível em: https://periodicos.ufsc.br/index.ph

p/extensio/article/view/1807-0221.2020v17n35p81. Acesso em: 15 mar. 2021.

GOLDMANN D. System failure versus personal accountability: the case for clean hands. New England Journal of Medicine, v. 355, n. 2, p. 121-123, 2006. Disponível em: https://www.nejm.org/doi/pdf/10.1056/nejmp068118. Acesso em: 15 dez. 2020.

HARAYAMA, R. M.; LIMA, J. G.; COSTA, E. N.; SANTOS, J. T. R. Curso COVID-19 e o processo de trabalho na atenção primária à saúde: territórios, atores e diálogos. Revista Capim Dourado: Diálogos em Extensão, Palmas, v. 3, n. 2, p. 70-80, 2020.

KAMPF, G.; TODT, D. S.; PFAENDER, E. S. Persistence of coronaviruses on inanimate surfaces and their inactivation with biocidal agents. Journal of hospital infection, v. 104, n. 3, p. 246-251, 2020. Disponível em: https://www.sciencedirect.com/science/article/pii/S019 5670120300463?casa_token=9g1o267cKrQAAAAA:I2fiLgUwsrbhv-3k61hTZUkz2 3N2hzlEvQVT6HGYHieMudC24pdBvsHZf1b04RrMQ99v5R5Iq_I. Acesso em: 03 mar. 2021. 
Curso "COVID-19: conhecendo para se prevenir - educação em saúde e ação extensionista

KINGSTON, L.; O'CONNELL, N.H; DUNNE, C. P. Hand hygiene-related clinical trials reported since 2010: A systematic review. Journal of Hospital Infection, v. 92, n. 4, p. 309-320, 2016. Disponível em: https://www.sciencedirect.com/science/article/pii/S0195670115004892 ?casa_token=do_x14FFIe0AAAAA:3MmyjFk-vacTIsObI7V7U9tbA1lxgVDUWLM2Wn JASThITTFKKUGz3jQ4d0wBigb9MzDKF-G-XxU. Acesso em: 30 nov. 2020.

MAIA, B. R.; DIAS, P. C. Ansiedade, depressão e estresse em estudantes universitários: o impacto da COVID-19. Estudos de Psicologia (Campinas), v. 37, 2020. Disponível em: https://www.scielo.br/scielo.php?script=sci_arttext\&pid=S0103-166X2020000100504\&tlng=pt. Acesso em: 27 fev. 2021.

MARRA, A.R.; EDMOND, M. B. New technologies to monitor healthcare worker hand hygiene. Clinical Microbiology and Infection, v. 20, n. 1, p. 29-33, 2014. Disponível em: https://www.sciencedirect.com/science/article/pii/S1198743X14601907. Acesso em: 25 nov. 2020.

MARRA, A. R. Avanços no controle das infecções. Einstein (São Paulo), v. 14, n. 1, p. 108109, 2016. Disponível em: https://www.scielo.br/scielo.php?pid=S1679-45082016000100108 \&script=sci_arttext\&tlng=pt. Acesso em 29 mar. 2021.

MELO, J. A. C.; SILVA, C.; ALVES, M. L. S.; MACHADO, I. S.; LAURINDO, M.; FIN, A. P. Extensão universitária na pandemia de covid-19: projeto Radiologia na comunidade, o uso da rede social e ambiente Virtual de aprendizagem. Saberes Plurais: Educação na Saúde, v. 4, n. 2, p. 49-60, 2020. Disponível em: https://www.seer.ufrgs.br/saberesplura is/article/view/108759. Acesso em: 13 jan. 2021.

NOAL, D. S.; PASSOS, M. F. D.; FREITAS, C. M. (org.). Recomendações e orientações em saúde mental e atenção psicossocial na COVID-19. Brasília: Fundação Oswaldo Cruz. 342 p., 2020. Disponível em: https://www.arca.fiocruz.br/handle/icict/44264. Acesso em 29 mar. 2021.

PASSAMAI, L. O.; COELHO, T. C.; CARVALHO, G. L. G. G.; CHAVENCO, P. S. C.; OLIVEIRA, N. S.; FERREIRA, S. M. I. L. Contribuições da extensão universitária como estratégia de assistência na promoção da segurança do paciente. Extensio: Revista Eletrônica de Extensão, Florianópolis, v. 17, n. 36, p. 79-93, 2020. Disponível em: https://dialnet.unirioja.es/servlet/articulo?codigo=7673090. Acesso em: 20 mar. 2021.

POST, L. K.; XAVIER, C. B.; SILVA, J. V. J. B. F.; SCHWONKE, N. R.; ARAUJO, C. F.; RAMSON, C. M. Projeto de extensão cetat em tempo de pandemia: novas experiências e reflexões. Expressa Extensão, v. 26, n. 1, p. 163-171, 2021. Disponível em: https://periodicos .ufpel.edu.br/ojs2/index.php/expressaextensao/article/view/19660. Acesso em: 07 fev. 2021.

SANTOS, A. A. M. Higienização das mãos no controle das infecções em serviços de saúde. RAS, v. 4, n. 15, p. 10-14, 2002. Disponível em: http://200.198.201.69/s ervicosaude/controle/higienizacao_mao.pdf. Acesso em: 20 nov. 2020.

SCHMIDT, B.; CREPALDI, M. A.; BOLZE, S. D. A.; NEIVA-SILVA, L.; DEMENECH, L. A. Saúde mental e intervenções psicológicas diante da pandemia do novo coronavírus (COVID-19). Estudos de Psicologia (Campinas), 37, e200063, 2020. Disponível em: 
Curso "COVID-19: conhecendo para se prevenir - educação em saúde e ação extensionista

https://preprints.scielo.org/index.php/scielo/preprint/view/58/version/62. Acesso em: 29 mar. 2021.

SCHUCHMANN, A. Z., SCHNORRENBERGER, B. L., CHIQUETTI, M. E., GAIKI, R. S., RAIMANN, B. W., \& MAEYAMA, M. A. Isolamento social vertical X Isolamento social horizontal: os dilemas sanitários e sociais no enfrentamento da pandemia de COVID19/Vertical social isolation X Horizontal social isolation: health and social dilemas in copping with the COVID-19 pandemic. Brazilian Journal of Health Review, v. 3, n. 2, p. 35563576, 2020. Disponível em: https://www.brazilianjournals.com/index.p hp/BJH $\mathrm{R} /$ article/view/9128. Acesso em 15 jan. 2021.

VARGAS, K. B.; LAWAL, S. Reflexões Biogeográficas acerca da origem, hipóteses, dispersão e distribuição dos Sars-CoV-2 (Corona Vírus). Geografia Ensino \& Pesquisa, v. 24, p. 19, 2020.

WORLD HEALTH ORGANIZATION. Advice for public. World Health Organization, 2020. Disponível em: https://www.who.int/emergencie s/disseas/novel-coronavirus-2019/advice-forpublic/myth-busters. Acesso em: 03 dez. 2020.

ZHOU, P., YANG, X. L., WANG, X. G., HU, B., ZHANG, L., ZHANG, W., SHI, Z. L. A pneumonia outbreak associated with a new coronavirus of probable bat origin. Nature, $v$. 579, n. 7798, p. 270-273, 2020. Disponível em: https://www.nature.com/articles/s41586-0202012-

7?fbclid=IwAR2hxnXb9nLWgA8xexEoNrCNH8WHqvHhhbN38aSm48AaH6fTzGMB1BLljf4. Acesso em: 04 nov. 2020

Recebido em: 27/04/2021

Aceito em: 01/12/2021 